\title{
Article
}

\section{Association between Appendicitis and Incident Systemic Sclerosis}

\author{
Kuang-Tsu Yang ${ }^{1,+}+\mathbb{D}$, James Cheng-Chung Wei ${ }^{2,3,4,+} \mathbb{D}$, Renin Chang $5,6\left(\mathbb{D}\right.$, Chi-Chien Lin ${ }^{7,8}(\mathbb{D})$ and \\ Hsin-Hua Chen $9,10,11,12,13,14,15, *$ (D)
}

1 Division of Gastroenterology and Hepatology, Department of Internal Medicine, Kaohsiung Veterans General Hospital, Kaohsiung 813414, Taiwan; ktyang1104@gmail.com

2 Graduate Institute of Integrated Medicine, China Medical University, Taichung 404333, Taiwan; wei3228@gmail.com

3 Department of Allergy, Immunology and Rheumatology, Chung Shan Medical University Hospital, Taichung 40201, Taiwan

4 Institute of Medicine, College of Medicine, Chung Shan Medical University, Taichung 40201, Taiwan

5 Department of Emergency Medicine, Kaohsiung Veterans General Hospital, Kaohsiung 813414, Taiwan; rhapsody1881@gmail.com

6 Department of Recreation Sports Management, Tajen University, Pingtung 90741, Taiwan

7 Institute of Biomedical Science and Rong Hsing Research Center for Translational Medicine, National Chung Hsing University, Taichung 402, Taiwan; lincc@dragon.nchu.edu.tw

8 Department of Medical Research, China Medical University Hospital, Taichung 404333, Taiwan

9 Department of Medical Research, Taichung Veterans General Hospital, Taichung 40705, Taiwan

10 Division of Allergy, Immunology and Rheumatology, Department of Internal Medicine, Taichung Veterans General Hospital, Taichung 40705, Taiwan

11 School of Medicine, National Yang-Ming University, Taipei 11221, Taiwan

12 Institute of Biomedical Science and Rong Hsing Research Centre for Translational Medicine, Chung Hsing University, Taichung 402, Taiwan

check for updates

Citation: Yang, K.-T.; Wei, J.C.-C.; Chang, R.; Lin, C.-C.; Chen, H.-H. Association between Appendicitis and Incident Systemic Sclerosis. J. Clin. Med. 2021, 10, 2337. https:// doi.org/10.3390/jcm10112337

Academic Editor: Redha Taiar

Received: 20 April 2021

Accepted: 24 May 2021

Published: 27 May 2021

Publisher's Note: MDPI stays neutral with regard to jurisdictional claims in published maps and institutional affiliations.

Copyright: (c) 2021 by the authors. Licensee MDPI, Basel, Switzerland. This article is an open access article distributed under the terms and conditions of the Creative Commons Attribution (CC BY) license (https:// creativecommons.org/licenses/by/ $4.0 /)$.
13 Institute of Public Health and Community Medicine Research Centre, National Yang-Ming University, Taipei 11221, Taiwan

14 Department of Industrial Engineering and Enterprise Information, Tunghai University, Taichung 407224, Taiwan

15 Division of General Internal Medicine, Department of Internal Medicine, Taichung Veterans General Hospital, Taichung 40705, Taiwan

* Correspondence: shc5555@hotmail.com or shc5556@gmail.com; Tel.: +886-0988328032 or +886-4-2359-2525 (ext. 3037)

$+\quad$ They contribute equally.

Abstract: Objective: This nationwide study aimed to investigate the association between newly diagnosed systemic sclerosis (SSc) and previous appendicitis history. Methods: A total of 1595 patients who were newly diagnosed with SSc were recruited as the SSc cases from the 2003 to 2012 claims data of the entire population in Taiwan. The other 15,950 individuals who had never been diagnosed with SSc during 2003 and 2012 were selected as the non-SSc controls to match the SSc cases. We defined that the index date as the first date of SSc diagnosis of SSc cases and the first date of ambulatory visit for any reason of non-SSc controls. Conditional logistic regression analysis was applied for the association between appendicitis and the risk of the incident SSc, tested by estimating odds ratios (ORs) with 95\% confidence intervals (CIs). Potential confounders, including the Charlson comorbidity index (CCI), a history of periodontal disease, salmonella infection, and intestinal infection, were controlled. We further designed sensitivity analyses by varying the definition of appendicitis according to the status of receiving primary appendectomy. Results: The mean age was 51 years in the case and control groups. Females accounted for $77.5 \%$. A total of 17 (1.1\%) out of 1595 SSc cases and 81 (0.5\%) out of 15,950 non-SSc controls had a history of appendicitis before the index date had a history of appendicitis. A significant association between appendicitis and the risk of SSc was confirmed (OR, 2.03; 95\% CI, 1.14-3.60) after adjusting potential confounders. $\mathrm{CCI} \geq 1(\mathrm{OR}, 8.48 ; 95 \% \mathrm{CI}, 7.50-9.58)$ and periodontal disease (OR, 1.55; 95\% CI, 1.39-1.74) were also significantly associated with the risk of SSc. The association between appendicitis and SSc risk remained robust using various definitions of appendicitis. Conclusion: Our study demonstrated appendicitis was associated with the incident SSc. CCI $\geq 1$ and periodontal disease also contributed to the risk of developing SSc. 
Keywords: appendicitis; systemic sclerosis; nationwide; population-based; case-control study

\section{Introduction}

Systemic sclerosis (SSc), also known as scleroderma, is a multidisciplinary autoimmune disease [1]. SSc is characterized by vascular and immune dysfunction, leading to fibrosis that can damage multiple organs [2]. SSc is divided into two subsets: limited systemic sclerosis (lcSSc) and diffuse systemic sclerosis (dsSSc). LcSSc leads to fibrosis of the skin of the face and limbs (distal to the knees and elbows), and dsSSc brings about fibrosis of the trunk and proximal parts of the limbs [3]. A 2018 global update on the epidemiology of SSc stated overall incidence rates of 8 to 56/1,000,000 person-year and prevalence rates of 38 to $341 / 1,000,000$ person-year [4]. Furthermore, a recent systematic review and meta-analysis revealed that the standardized mortality ratio of SSc reached a high value of 3.45 [5]. SSc is still a great life-threatening disease to patients and brings numerous challenges to clinicians.

For early recognition of probable SSc development, plenty of risk factors of SSc were identified in previous research. A family history of SSc can contribute to a 13-fold higher risk of developing SSC in the patients' first-degree relatives and 15-fold higher in patients' siblings than that in the general population [6]. Genes such as BANK1, BLK, CD226, etc., are significantly associated with SSc [6]. In females, SSc is approximately 8-9 times more frequent than in males, but male patients will encounter a worse prognosis [7]. Environmental pathogenic factors involving silica, solvents (white spirit, trichloroethylene, aromatic solvents, chlorinated solvents, ketones, and welding fumes) [8], and heavy metals (antimony, cadmium, lead, mercury, molybdenum, palladium, and zinc) have been proven risk factors of SSc [9]. Though many efforts were made on the investigation of identifying risk factors of SSc, there are still many areas not found in correlation with SSc development.

The appendix has been long thought to be an evolutionary remnant of little significance to normal physiology, but it has more recently been identified as an important component of mammalian mucosal immune function, particularly B-lymphocyte-mediated immune responses and extrathymically derived T-lymphocytes. It also serves as a place for further development of $\mathrm{T}$ and $\mathrm{B}$ cell areas of follicles within the lymphoid tissue $[10,11]$. The biofilm in the appendix is thought to act as a "safe house" for commensal bacteria under the assistance of secretory $\operatorname{IgA}(\operatorname{sIg} \mathrm{A})$ and mucin by increasing adhesive growth of the agglutinated gut flora [11]. Many studies have suggested that appendicitis or appendectomy may be associated with numerous diseases, such as ulcerative colitis [12], Crohn's disease [13,14], and Parkinson's disease [15]. However, the association of appendicitis or appendectomy with SSc still remained unaddressed, and there lacks a large population-based study before.

To solve this knowledge gap, we launched a nationwide, population-based, casecontrol study to investigate the association between appendicitis or appendectomy and SSc in Taiwan.

\section{Materials and Methods}

\subsection{Ethics Statement}

This study was approved by the Institutional Review Board of Taichung Veterans General Hospital (TCVGH CE14149B-1). This is a retrospective study, and all identified patients were anonymous. Therefore, there was no need for obtaining informed patient consent.

\subsection{Data Source}

The National Health Insurance (NHI) Program was implemented on 1 March 1995, and it has since covered more than $99 \%$ of the population in Taiwan. The National Health Insurance Research Database (NHIRD), derived from the NHI Program in 1997, includes patient characteristics (such as age, gender, and date of birth), dates of admission and 
discharge, the International Classification of Diseases, Ninth Revision, Clinical Modification (ICD-9-CM) codes of diagnoses and procedures, medication prescriptions, and medical expenditure covered by the NHI. The cases were selected from the whole population and controls from the Longitudinal Health Insurance Database 2000 (LHID 2000), with claims data (from 1997 to 2013) of 1 million beneficiaries. We acknowledged that the LHID 2000 database had the representative power of the national population [16].

\subsection{Study Design}

This is a nationwide, population-based, case-control study. SSc is defined as ICD9-CM Code 710.1. From 2006 to 2012, we extracted subjects from the whole population autoimmune database who had a diagnosis of SSc with at least three outpatient visits or one inpatient visit and a catastrophic illness certificate of SSc. Patients with major or catastrophic illnesses (e.g., cancer, cirrhosis, heart failure, or autoimmune diseases) in Taiwan are recruited into the NHI registry system and get catastrophic illness certificates exempt from copayment. A routine validation of diagnoses is performed by at least two specialists from the Bureau of NHI (BNHI). They carefully review the original medical history, laboratory data, images, and pathology of all patients with catastrophic illness registration. Catastrophic illness certificates are delivered by the BNHI to those who had the major illness criteria. The database does not involve laboratory data and radiographic images, but the BNHI routinely reviews and edits diagnoses accuracy by randomly sampling charts of a patient, which will enhance coding accuracy.

Additionally, we chose individuals from the LHID with ambulatory records who never had a diagnosis of SSc during 2006 and 2012 and were matched with SSc cases (1:10) for age, sex, and the index date as non-SSc controls. The flowchart of patient enrollment is shown in Figure 1. The index date was defined as the first date of SSc diagnosis in the SSc group and the first date of ambulatory visit for any reason in the control group.

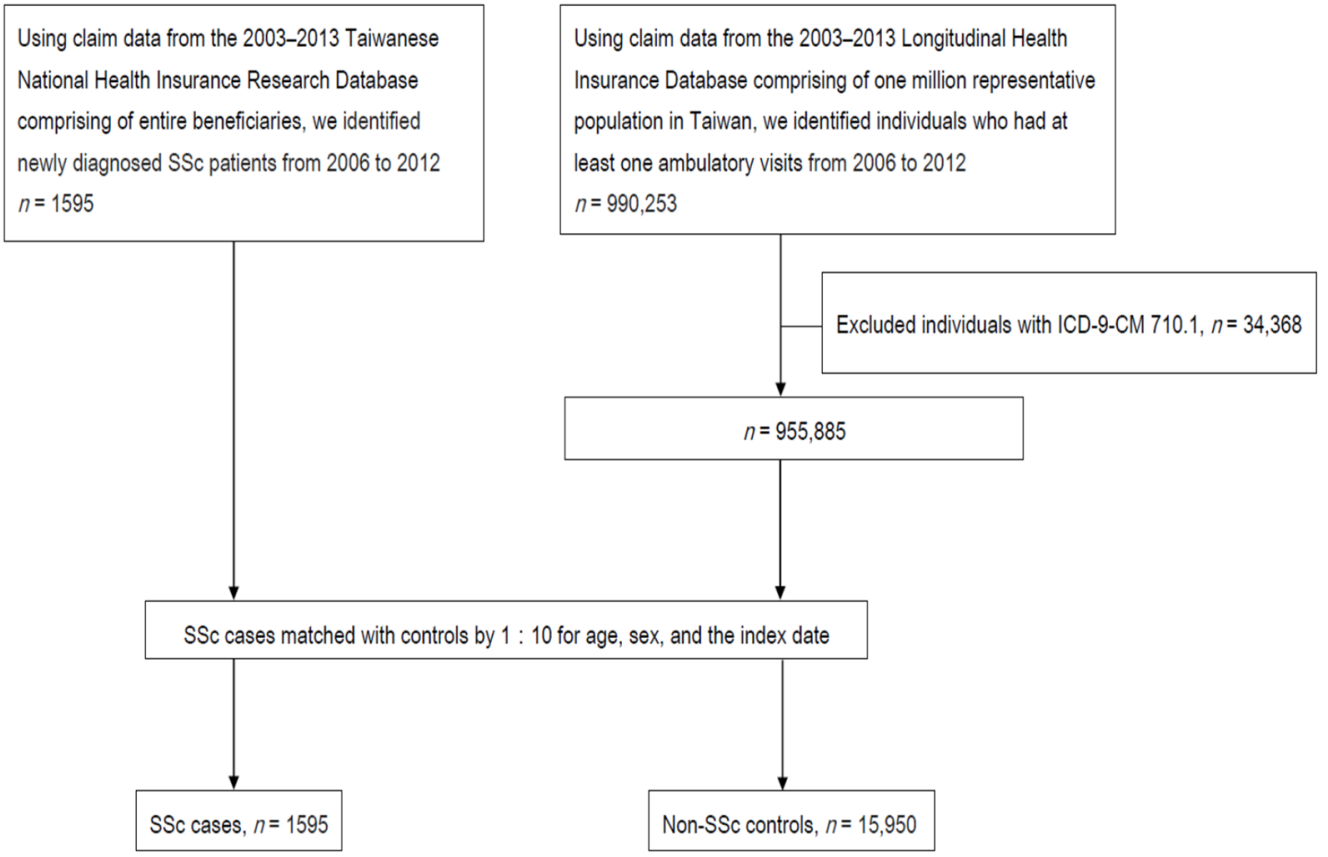

Figure 1. Study flowchart.

\subsection{Definition of a History of Appendicitis}

Subjects were considered to have a history of appendicitis if they had at least one ambulatory visit or inpatient visit with a diagnosis of appendicitis (ICD-9-CM Codes 540-543) before the index date. 


\subsection{Potential Confounders}

Potential confounders included a history of periodontal disease (ICD-9-CM 523) [17], salmonella (ICD-9-CM 003) [18], and ill-defined intestinal infections (ICD-9-CM 009) [19] before the index date, as well as a Charlson comorbidity index (CCI) within one year before the index date. Deyo et al. indicated that CCI could be applied to evaluate the degree of clinically general comorbid situations [20].

\subsection{Sensitivity Analysis}

For certifying the robust association between appendicitis and SSC, we also performed sensitivity analyses by varying the definition of appendicitis according to the status of receiving primary appendectomy. Different definitions of appendicitis involved appendicitis (ICD9: 540-543), primary appendectomy (ICD9 Procedure Code: 47.0), appendicitis and primary appendectomy, and appendicitis or primary appendectomy.

\subsection{Statistical Analysis}

We compared baseline characteristics between cases and controls using Pearson's $\chi^{2}$ test for categorical variables and a $t$-test for continuous variables. Conditional logistic regression was used to examine the influence of appendicitis and other potential confounders on the risk of SSc development, as shown by odds ratios (ORs) with $95 \%$ confidence intervals (CIs). A two-tailed value of $p<0.05$ was considered statistically significant. All statistical analyses were performed using SAS version 9.3 (SAS Institute, Inc., Cary, NC, USA).

\section{Results}

Figure 1 shows the flowchart of patient recruitment. We identified 1595 SSc cases and 15,950 non-SSc controls. Table 1 reveals the demographic data and clinical characteristics of SSc cases and non-SSc controls. The enrolled individuals' ages range from 4 to 91 years old. Among them, those who are over 45 years old accounted for $66.8 \%$. The ratios of individuals with CCI more than and equal to one (59.6\% vs. $19.2 \%)$, myocardial infarction $(0.5 \%$ vs. $0.2 \%)$, congestive heart failure $(3.4 \%$ vs. $0.7 \%)$, peripheral vascular disease ( $3.1 \%$ vs. $0.2 \%)$, chronic obstructive pulmonary disease (COPD) $(9.8 \%$ vs. $3.0 \%)$, connective tissue disease ( $39.6 \%$ vs. $0.3 \%)$, peptic ulcer disease ( $11 \%$ vs. $4.4 \%)$, mild liver disease ( $5.1 \%$ vs. $2.1 \%)$, diabetes mellitus with end-organ damage ( $2.3 \%$ vs. $1.5 \%)$, hemiplegia $(0.6 \%$ vs. $0.2 \%)$, moderate to severe renal disease ( $5.5 \%$ vs. $1.1 \%)$, tumor $(6.6 \%$ vs. $2.1 \%)$, and metastatic solid tumor $(1.0 \%$ vs. $0.2 \%)$ are more in SSc cases than in non-SSc. Similarly, appendicitis $(1.1 \%$ vs. $0.5 \%)$, primary appendectomy ( $0.9 \%$ vs. $0.5 \%)$, appendicitis and primary appendectomy $(0.9 \%$ vs. $0.5 \%)$, appendicitis or primary appendectomy $(1.1 \%$ vs. $0.5 \%)$, ill-defined intestinal infections ( $14.4 \%$ vs. $12.7 \%)$, and periodontal disease $(48.5 \%$ vs. $37.2 \%)$ all have a trend of higher ratio in SSc cases than non-SSc controls.

Our study uses a conditional logistic regression model to investigate the association of SSc risk with appendicitis, CCI, periodontal disease, salmonella, and ill-defined intestinal infections (Table 2). We found that appendicitis, CCI $\geq 1$, periodontal disease, and ill-defined intestinal infections are associated with SSc significantly in univariable analysis (appendicitis, OR, 2.11; 95\% CI, 1.25-3.57; CCI $\geq 1$, OR = 8.64, 95\% CI = 7.64-9.76; periodontal disease, $\mathrm{OR}=1.64,95 \% \mathrm{CI}=1.48-1.83$; ill-defined intestinal infections, $\mathrm{OR}=1.17$, $95 \% \mathrm{CI}=1.004-1.35)$. In multivariable analysis, appendicitis was still a significant risk factor of SSc (OR, 2.03; 95\% CI, 1.14-3.60). CCI $\geq 1$ and periodontal disease were also risk factors of SSc. 
Table 1. Demographic data and clinical characteristics between the two study groups.

\begin{tabular}{|c|c|c|c|}
\hline & Control & Case & \\
\hline & $(n=15,950)$ & $(n=1595)$ & $p$-Value \\
\hline Age, years (mean $\pm S D)$ & $51 \pm 15$ & $51 \pm 15$ & 1 \\
\hline Gender & & & 1 \\
\hline Female & $12,360(77.5)$ & $1236(77.5)$ & \\
\hline Male & $3590(22.5)$ & $359(22.5)$ & \\
\hline Appendicitis & $81(0.5)$ & $17(1.1)$ & 0.004 \\
\hline Primary appendectomy & $74(0.5)$ & $15(0.9)$ & 0.011 \\
\hline Appendicitis and primary appendectomy & $73(0.5)$ & $15(0.9)$ & 0.009 \\
\hline Appendicitis or primary appendectomy & $82(0.5)$ & $17(1.1)$ & 0.005 \\
\hline Salmonella & $65(0.4)$ & $8(0.5)$ & 0.578 \\
\hline Ill-defined intestinal infections & $2020(12.7)$ & $230(14.4)$ & 0.047 \\
\hline Periodontal disease & $5936(37.2)$ & $774(48.5)$ & $<0.001$ \\
\hline CCI group & & & $<0.001$ \\
\hline 0 & $12,888(80.8)$ & $645(40.4)$ & \\
\hline$\geq 1$ & $3062(19.2)$ & $950(59.6)$ & \\
\hline Myocardial infarction & $24(0.2)$ & $8(0.5)$ & 0.002 \\
\hline Congestive heart failure & $109(0.7)$ & $55(3.4)$ & $<0.001$ \\
\hline Peripheral vascular disease & $36(0.2)$ & $50(3.1)$ & $<0.001$ \\
\hline Cerebrovascular disease & $439(2.8)$ & $52(3.3)$ & 0.241 \\
\hline Dementia & $75(0.5)$ & $5(0.3)$ & 0.376 \\
\hline COPD & $485(3.0)$ & $156(9.8)$ & $<0.001$ \\
\hline Connective tissue disease & $53(0.3)$ & $631(39.6)$ & $<0.001$ \\
\hline Peptic ulcer disease & $700(4.4)$ & $175(11)$ & $<0.001$ \\
\hline Mild liver disease & $332(2.1)$ & $82(5.1)$ & $<0.001$ \\
\hline Diabetes mellitus & $1158(7.3)$ & $113(7.1)$ & 0.797 \\
\hline Diabetes mellitus with end-organ damage & $246(1.5)$ & $37(2.3)$ & 0.019 \\
\hline Hemiplegia & $35(0.2)$ & $10(0.6)$ & 0.002 \\
\hline Moderate to severe renal disease & $181(1.1)$ & $87(5.5)$ & $<0.001$ \\
\hline Tumor & $341(2.1)$ & $105(6.6)$ & $<0.001$ \\
\hline Moderate or severe liver disease & $13(0.1)$ & $3(0.2)$ & 0.179 \\
\hline Metastatic solid tumor & $34(0.2)$ & $16(1.0)$ & $<0.001$ \\
\hline AIDS & $1(0)$ & $0(0)$ & 0.752 \\
\hline
\end{tabular}

Abbreviations: SD, standard deviation; CCI, Charlson comorbidity index; COPD, chronic obstructive pulmonary disease; AIDS, acquired immune deficiency syndrome.

Table 2. Conditional logistic regression analyses for risk factors of SSc.

\begin{tabular}{ccc}
\hline & Univariate Analysis & Multivariate Analysis \\
\hline & OR $\mathbf{( 9 5 \% ~ C I )}$ & OR (95\% CI) \\
\hline Diagnosed with appendicitis & $2.11(1.25-3.57)$ & $2.03(1.14-3.60)$ \\
CCI $\geq 1$ & $8.64(7.64-9.76)$ & $8.48(7.50-9.58)$ \\
Periodontal disease & $1.64(1.48-1.83)$ & $1.55(1.39-1.74)$ \\
Salmonella & $1.23(0.59-2.58)$ & $0.97(0.43-2.18)$ \\
Ill-defined intestinal infections & $1.17(1.004-1.35)$ & $1.00(0.85-1.17)$ \\
\hline
\end{tabular}

Abbreviations: SSc, systemic sclerosis; CCI, Charlson comorbidity index.

Our sensitivity analysis for researching the association of different diagnosis definitions of appendicitis with SSc are shown in Table 3. Different diagnosis codes include appendicitis, primary appendectomy, appendicitis and primary appendectomy, and appendicitis or primary appendectomy. We discover that different diagnosis definitions of appendicitis are all significant risk factors of SSc, and the ORs are approximately two. In other words, those patients who had a history of appendicitis have a two-fold risk of suffering from SSc compared with those without a history of appendicitis. 
Table 3. Sensitivity analysis.

\begin{tabular}{cccccc}
\hline & \multicolumn{2}{c}{$\begin{array}{c}\text { Control } \\
(\boldsymbol{n = 1 5 , 9 5 0 )}\end{array}$} & \multicolumn{2}{c}{$\begin{array}{c}\text { Case } \\
(\boldsymbol{n}=\mathbf{1 5 9 5 )}\end{array}$} & $\begin{array}{c}\text { Multivariate } \\
\text { Analysis }\end{array}$ \\
\hline & Event (\%) & $\begin{array}{c}\text { Duration (Year) } \\
\text { (Mean } \pm \text { SD) }\end{array}$ & Event (\%) & $\begin{array}{c}\text { Duration (Year) } \\
\text { (Mean } \pm \text { SD) }\end{array}$ & OR (95\% CI) \\
\hline Appendicitis & $81(0.5)$ & $3.7 \pm 2.2$ & $17(1.1)$ & $3.7 \pm 2.1$ & $2.03(1.14-3.60)$ \\
Primary appendectomy & $74(0.5)$ & $3.6 \pm 2.1$ & $15(0.9)$ & $3.7 \pm 2.1$ & $1.93(1.06-3.54)$ \\
Appendicitis and Primary appendectomy & $73(0.5)$ & $3.6 \pm 2.1$ & $15(0.9)$ & $3.7 \pm 2.1$ & $1.97(1.07-3.61)$ \\
Appendicitis or Primary appendectomy & $82(0.5)$ & $3.7 \pm 2.2$ & $17(1.1)$ & $3.7 \pm 2.1$ & $1.99(1.13-3.53)$ \\
\hline
\end{tabular}

\section{Discussion}

To our knowledge, this nationwide, population-based, case-control study firstly utilized longitudinal administrative data to examine the strength of the association between appendicitis and SSc. The main finding of this study was a statistically significant association between the history of appendicitis and the risk of incident SSc after adjustment for periodontal disease, CCI, salmonella, and ill-defined intestinal infection. The association between appendicitis and SSc risk is still robust using various definitions of appendicitis correlated with the status of primary appendectomy.

The precise mechanism between appendicitis SSc was not well established currently. After the literature review, we propose two hypotheses that might explain this phenomenon. The first hypothesis is that the appendix has an immunologically regulatory role. $T$ cells in the lamina propria of the appendix express more of the integrin subunit $\beta_{7}$ compared to $T$ and $B$ cells throughout other sites of the gut. Two kinds of integrin- $\alpha_{4} \beta_{7}$ and $\alpha_{E} \beta_{7}$ interact with lymphocytes. Of note, $\alpha_{E} \beta_{7}$ is capable of stimulating differentiation forkhead box protein 3 (FoxP3) $)^{+} \mathrm{T}_{\text {reg }}$ cells. As long as this differentiation is suppressed, a proinflammatory state could occur [11]. Subsequent proinflammatory cytokines (type I interferons, TGF- $\beta$, interleukin 17 , and interleukin 23) and mediators (leptin, adiponectin, chimerin, and interleukin 6) would promote the pathogenesis of SSc [21].

The second hypothesis is that intestinal microbiota change was considered a possible pathogenetic factor of SSc after appendectomy or appendicitis. Research has shown SSc patients had significantly higher levels of pathobiont genera, such as Fusobacterium, Prevotella, and Proteobacteria genera, compared with controls [22]. Fusobacterium species belong to the Gram-negative anaerobes category and appear mostly in the oral cavity. If they are present in the colon, they will show their invasive ability and translocate into the systemic circulation. They could induce bacteremia, organ abscesses, possibly coronary artery disease [23,24], and inflammatory bowel disease. Fusobacterium species could bring about more invasive and proinflammatory properties in cultured epithelial cell assays than those strains isolated from healthy individuals, which implies that Fusobacterium species are linked with inflammatory diseases [25]. Prevotella species were more abundant in SSc patients than healthy people. These genera are increased in patients with Crohn's disease or rheumatoid arthritis $[26,27]$. A study had also demonstrated that there was a significantly increased level of Proteobacteria in patients with Crohn's disease [28]. Mucosal biopsies showed a significantly higher level of Proteobacteria in patients with extensive and active ulcerative colitis than in patients with a limited extent and less active disease [29]. Some studies reported the normal human appendix harbors populations of Fusobacterium, Prevotella, and Proteobacteria genera that are generally absent in fecal samples from healthy adults and children $[30,31]$. After appendicitis or appendectomy, Fusobacterium, Prevotella, and Proteobacteria genera will lose their harbor and may initiate the inflammation cascade and the subsequent development of SSc.

Our results demonstrated that periodontal disease was the risk factor of SSc development. The potential mechanism might be explained by the association between Prevotella, inflammation, and periodontitis [32]. Prevotella was confirmed in biofilms of gingivitis and periodontitis [33] and was well identified as a driver of neutrophil recruitment, proinflam- 
matory cytokines, and metalloproteinase expression attributing destruction of connective tissues and alveolar bone [34]. Prevotella nigrescens in mice can induce periodontal disease and promote immune responses such as increasing T helper type 17 (Th17) (i.e., interleukin (IL-17)) and Th1 (interferon- $\gamma($ IFN- $\gamma)$ ) cytokine production by lymph node T cells compared with uninfected mice [35]. IL-17 was found capable of indirectly enhancing the fibrotic process in experimental animal models of skin and lung fibrosis. IL-17 could induce inflammation by recruiting inflammatory cells, stimulating the production of TGF- $\beta$ and other profibrotic mediators, and inhibiting autophagy [36]. On the other hand, serum IFN- $\gamma$ levels were higher in SSc patients than in individuals without SSc. Furthermore, IFN- $\gamma$ is associated with pulmonary arterial hypertension and positively correlated with mean systolic pulmonary arterial pressure, which suggested its role in pulmonary manifestations of SSc patients [37].

Salmonella infection was considered as a potential risk factor of SSc in our study based on the previous research [18], which indicated that nontyphoidal salmonella bacteremia causes substantial morbidity and mortality in patients with connective tissue disease, including scleroderma. However, in our study, the final results showed there was no significant association between salmonella infection and SSc. Such inconsistency may be explained by the fact that we considered salmonella infection as a confounder but not salmonella bacteremia, which suggested a more severe form of salmonella infection that might lead to a greater influence on SSc risk.

CCI $\geq 1$ was also significantly associated with the risk of developing SSc in our study. We hypothesized that before the index date, patients with SSc would first have constitutional symptoms and signs, including cutaneous manifestations (e.g., pruritus, edema, skin hyperpigmentation), gastrointestinal involvement (e.g., dysphagia, choking, heartburn sensation, hoarseness, bloating), pulmonary involvement (e.g., breathlessness on exertion, nonproductive cough), cardiac manifestations (e.g., chest pain), renal involvement (e.g., impaired renal reserve, hypertension, microalbuminuria), and neuromuscular involvement (e.g., muscle atrophy, weakness, myopathy, neuropathy). Due to the above-mentioned symptoms and signs, patients were easily diagnosed with other comorbidities before the diagnosis of SSc. Therefore, CCI $\geq 1$ was also identified as a risk factor of SSc in our study.

The strength of our study is using population-based data to minimize selection bias. However, we acknowledged that there are some limitations of our study. First, the NHIRD does not include personal information regarding lifestyles, body mass index values, smoking, and alcohol use. Smoking currently is still not clarified as a certain risk factor of SSc [38]. In order to minimize these biases, we had adjusted COPD and comorbidities to proxy these lifestyle-related diseases. Second, patients' laboratory parameters and family history were not available in this dataset, which are also confounders of the development of SSc. Third, coding errors might happen in the NHIRD. To alleviate the bias, we recruited patients under the criteria of a diagnosis of SSc with at least three outpatient visits or one inpatient visit and a catastrophic illness certificate of SSc. Finally, our results may not be able to be generalized to non-Taiwanese populations.

\section{Conclusions}

Our nationwide, population-based, case-control study demonstrated an association between appendicitis and the risk of SSc. Further mechanistic studies are warranted to elucidate the causal relationship between appendicitis and SSc development.

Author Contributions: Conceptualization: J.C.-C.W. and H.-H.C. Data curation: K.-T.Y., J.C.-C.W., R.C., C.-C.L., and H.-H.C. Formal analysis: K.-T.Y., J.C.-C.W., C.-C.L., and H.-H.C. Funding acquisition: not applicable. Investigation: K.-T.Y., J.C.-C.W., and H.-H.C. Methodology: H.-H.C. Project administration: J.C.-C.W. and H.-H.C. Resources: H.-H.C. Software: C.-C.L. and H.-H.C. Supervision: H.-H.C. Validation: K.-T.Y., J.C.-C.W., and H.-H.C. Visualization: J.C.-C.W., R.C., and H.-H.C. Writing-original draft preparation: K.-T.Y. and J.C.-C.W. Writing-review and editing: H.-H.C. All authors have read and agreed to the published version of the manuscript.

Funding: This research received no external funding. 
Institutional Review Board Statement: This study was approved by the Institutional Review Board of Taichung Veterans General Hospital (TCVGH CE14149B-1).

Informed Consent Statement: This is a retrospective study, and all identified patients were anonymous. Therefore, there was no need for obtaining informed patient consent.

Data Availability Statement: Data are available from the National Health Insurance Research Database (NHIRD) published by Taiwan National Health Insurance (NHI) Bureau. Due to legal restrictions imposed by the government of Taiwan in relation to the "Personal Information Protection Act", data cannot be made publicly available.

Acknowledgments: We would like to thank the Biostatistics Task Force of Taichung Veterans General Hospital, Taichung, Taiwan, ROC, for assistance with statistical analyses. We thank the members of the Bureau of National Health Insurance, Department of Health, and the National Health Research Institutes for providing and managing, respectively, the National Health Insurance Research Database.

Conflicts of Interest: The authors declare no conflict of interest.

Abbreviations: SSc: systemic sclerosis; lcSSc: limited systemic sclerosis; dsSSc: diffuse systemic sclerosis; NHI: National Health Insurance; NHIRD: National Health Insurance Research Database; ICD-9-CM: International Classification of Diseases, Ninth Revision, Clinical Modification; LHID 2000: Longitudinal Health Insurance Database 2000; BNHI: Bureau of NHI; CCI: Charlson comorbidity index; ORs: odds ratios; CIs: confidence intervals; FoxP3: forkhead box protein 3; Th17: T helper type 17; IL-17: interleukin; IFN- $\gamma$ : interferon- $\gamma$.

\section{References}

1. Sobolewski, P.; Maślińska, M.; Wieczorek, M.; Łagun, Z.; Malewska, A.; Roszkiewicz, M.; Nitskovich, R.; Szymańska, E.; Walecka, I. Systemic sclerosis-Multidisciplinary disease: Clinical features and treatment. Reumatologia 2019, 57, $221-233$. [CrossRef] [PubMed]

2. Stern, E.P.; Denton, C.P. The Pathogenesis of Systemic Sclerosis. Rheum. Dis. Clin. N. Am. 2015, 41, 367-382. [CrossRef]

3. Barsotti, S.; Stagnaro, C.; Della Rossa, A. Systemic sclerosis: A critical digest of the recent literature. Clin. Exp. Rheumatol. 2015, 33.

4. Ingegnoli, F.; Ughi, N.; Mihai, C. Update on the epidemiology, risk factors, and disease outcomes of systemic sclerosis. Best Pract. Res. Clin. Rheumatol. 2018, 32, 223-240. [CrossRef]

5. Pokeerbux, M.R.; Giovannelli, J.; Dauchet, L.; Mouthon, L.; Agard, C.; Lega, J.C.; Allanore, Y.; Jego, P.; Bienvenu, B.; Berthier, S.; et al. Survival and prognosis factors in systemic sclerosis: Data of a French multicenter cohort, systematic review, and meta-analysis of the literature. Arthritis Res. 2019, 21, 1-12. [CrossRef]

6. Korman, B.D.; Criswell, L.A. Recent advances in the genetics of systemic sclerosis: Toward biological and clinical significance. Curr. Rheumatol. Rep. 2015, 17, 21. [CrossRef]

7. Freire, M.; Rivera, A.; Sopeña, B.; Vilella, C.T.; Guillén-Del-Castillo, A.; Argüelles, D.C.; Rubio, J.L.C.; Rivas, M.R.; Martínez, L.T.; Parra, J.A.T.; et al. Clinical and epidemiological differences between men and women with systemic sclerosis: A study in a Spanish systemic sclerosis cohort and literature review. Clin. Exp. Rheumatol. 2017, 35, 89-97.

8. Rubio-Rivas, M.; Moreno, R.; Corbella, X. Occupational and environmental scleroderma. Systematic review and meta-analysis. Clin. Rheumatol. 2017, 36, 569-582. [CrossRef]

9. Marie, I.; Gehanno, J.-F.; Bubenheim, M.; Duval-Modeste, A.-B.; Joly, P.; Dominique, S.; Bravard, P.; Noël, D.; Cailleux, A.-F.; Benichou, J.; et al. Systemic sclerosis and exposure to heavy metals: A case control study of 100 patients and 300 controls. Autoimmun. Rev. 2017, 16, 223-230. [CrossRef] [PubMed]

10. Zahid, A. The vermiform appendix: Not a useless organ. J. Coll. Physicians Surg. Pak. 2004, 14, 256-258. [PubMed]

11. Kooij, I.A.; Sahami, S.; Meijer, S.L.; Buskens, C.J.; Velde, A.A.T. The immunology of the vermiform appendix: A review of the literature. Clin. Exp. Immunol. 2016, 186, 1-9. [CrossRef]

12. Lowenfels, A.B.; Maisonneuve, P. Appendectomy and protection against ulcerative colitis. N. Engl. J. Med. 2001, $345,4$.

13. Andersson, R.E.; Olaison, G.; Tysk, C.; Ekbom, A. Appendectomy is followed by increased risk of Crohn's disease. Gastroenterology 2003, 124, 40-46. [CrossRef] [PubMed]

14. Caserta, L.; De Filippo, F.R.; Riegler, G. Relationship between anamnestic evidence of appendectomy and onset and clinical course of Crohn's disease. Am. J. Gastroenterol. 2002, 97, 207-208. [CrossRef]

15. Svensson, E.; Horváth-Puhó, E.; Stokholm, M.G.; Sørensen, H.T.; Henderson, V.W.; Borghammer, P. Appendectomy and risk of Parkinson's disease: A nationwide cohort study with more than 10 years of follow-up. Mov. Disord. 2016, 31, 1918-1922. [CrossRef]

16. Bureau of National Health Insurance D, Executive Yuan, Taiwan: Database IttNHIR, (NHIRD). Available online: https://nhird. nhri.org.tw/ (accessed on 10 July 2020).

17. Leung, W.K.; Chu, C.H.; Mok, M.Y.; Yeung, K.W.; Ng, S.K. Periodontal status of adults with systemic sclerosis: Case-control study. J. Periodontol. 2011, 82, 1140-1145. [CrossRef] 
18. Huang, C.-F.; Chen, P.-L.; Liu, M.-F.; Lee, C.-C.; Lee, N.-Y.; Chang, C.-M.; Lee, H.-C.; Wu, C.-J.; Ko, W.-C. Nontyphoidal Salmonella bacteremia in patients with connective tissue diseases. J. Microbiol. Immunol. Infect. 2012, 45, 350-355. [CrossRef]

19. Johnson, M.E.; Franks, J.M.; Cai, G.; Mehta, B.K.; Wood, T.A.; Archambault, K.; Pioli, P.A.; Simms, R.W.; Orzechowski, N.; Arron, S.; et al. Microbiome dysbiosis is associated with disease duration and increased inflammatory gene expression in systemic sclerosis skin. Arthritis Res. 2019, 21, 1-11. [CrossRef]

20. Deyo, R.A.; Cherkin, D.C.; Ciol, M.A. Adapting a clinical comorbidity index for use with ICD-9-CM administrative databases. J. Clin. Epidemiol. 1992, 45, 613-619. [CrossRef]

21. Sticherling, M. Systemic sclerosis—the dermatological perspective. J. Dtsch. Dermatol. Ges. 2019, 17, 716-728. [CrossRef]

22. Volkmann, E.R.; Chang, Y.-L.; Barroso, N.; Furst, D.E.; Clements, P.J.; Gorn, A.H.; Roth, B.E.; Conklin, J.L.; Getzug, T.; Borneman, J.; et al. Association of Systemic Sclerosis With a Unique Colonic Microbial Consortium. Arthritis Rheumatol. 2016, 68, 1483-1492. [CrossRef] [PubMed]

23. Roberts, G.L. Fusobacterial infections: An underestimated threat. Br. J. Biomed. Sci. 2000, 57, 156-162.

24. Koren, O.; Spor, A.; Felin, J.; Fak, F.; Stombaugh, J.; Tremaroli, V.; Behre, C.J.; Knight, R.; Fagerberg, B.; Ley, R.E.; et al. Human oral, gut, and plaque microbiota in patients with atherosclerosis. Proc. Natl. Acad. Sci. USA 2011, 108, 4592-4598. [CrossRef]

25. Strauss, J.; Kaplan, G.G.; Beck, P.L.; Rioux, K.; Panaccione, R.; DeVinney, R.; Lynch, T.; Allen-Vercoe, E. Invasive potential of gut mucosa-derived fusobacterium nucleatum positively correlates with IBD status of the host. Inflamm. Bowel Dis. 2011, 17, 1971-1978. [CrossRef]

26. Benjamin, J.L.; Hedin, C.R.; Koutsoumpas, A.; Ng, S.C.; McCarthy, N.E.; Prescott, N.J.; Pessoa-Lopes, P.; Mathew, C.G.; Sanderson, J.; Hart, A.L.; et al. Smokers with active Crohn's disease have a clinically relevant dysbiosis of the gastrointestinal microbiota. Inflamm. Bowel Dis. 2012, 18, 1092-1100. [CrossRef]

27. Scher, J.U.; Sczesnak, A.; Longman, R.S.; Segata, N.; Ubeda, C.; Bielski, C.; Rostron, T.; Cerundolo, V.; Pamer, E.G.; Abramson, S.B.; et al. Expansion of intestinal Prevotella copri correlates with enhanced susceptibility to arthritis. Elife 2013, 2, e01202. [CrossRef] [PubMed]

28. Vester-Andersen, M.K.; Mirsepasi, H.C.; Prosberg, M.V.; Mortensen, C.O.; Träger, C.; Skovsen, K.; Thorkilgaard, T.; Nøjgaard, C.; Vind, I.; Krogfelt, K.A.; et al. Increased abundance of proteobacteria in aggressive Crohn's disease seven years after diagnosis. Sci. Rep. 2019, 9, 1-10. [CrossRef]

29. Walujkar, S.A.; Dhotre, D.P.; Marathe, N.P.; Lawate, P.S.; Bharadwaj, R.S.; Shouche, Y.S. Characterization of bacterial community shift in human Ulcerative Colitis patients revealed by Illumina based 16S rRNA gene amplicon sequencing. Gut Pathog. 2014, 6, 22. [CrossRef]

30. Guinane, C.M.; Tadrous, A.; Fouhy, F.; Ryan, C.A.; Dempsey, E.M.; Murphy, B.; Andrews, E.; Cotter, P.; Stanton, C.; Ross, R.P. Microbial Composition of Human Appendices from Patients following Appendectomy. mBio 2013, 4. [CrossRef]

31. Rogers, M.B.; Brower-Sinning, R.; Firek, B.; Zhong, D.; Morowitz, M.J. Acute appendicitis in children is associated with a local expansion of Fusobacteria. Clin. Infect. Dis. 2016, 63, 71-78. [CrossRef]

32. Dahlén, G. Black-pigmented Gram-negative anaerobes in periodontitis. FEMS Immunol. Med. Microbiol. 1993, 6, 181-192. [CrossRef]

33. Berezow, A.B.; Darveau, R.P. Microbial shift and periodontitis. Periodontol. 2000 2011, 55, 36-47. [CrossRef]

34. Cekici, A.; Kantarci, A.; Hasturk, H.; Van Dyke, T.E. Inflammatory and immune pathways in the pathogenesis of periodontal disease. Periodontol. 2000 2014, 64, 57-80. [CrossRef] [PubMed]

35. de Aquino, S.G.; Abdollahi-Roodsaz, S.; Koenders, M.I.; van de Loo, F.A.J.; Pruijn, G.J.M.; Marijnissen, R.J.; Walgreen, B.; Helsen, M.M.; van den Bersselaar, L.A.; de Molon, R.S.; et al. Periodontal pathogens directly promote autoimmune experimental arthritis by inducing a TLR2- and IL-1-driven Th17 response. J. Immunol. 2014, 192, 4103-4111. [CrossRef] [PubMed]

36. Chizzolini, C.; Dufour, A.M.; Brembilla, N.C. Is there a role for IL-17 in the pathogenesis of systemic sclerosis? Immunol. Lett. 2018, 195, 61-67. [CrossRef]

37. Bălănescu, P.; Lădaru, A.; Bălănescu, E.; Nicolau, A.; Băicuş, C.; Dan, G.A. IL-17, IL-6 and IFN- $\gamma$ in Systemic Sclerosis Patients. Rom. J. Intern. Med. 2015, 53, 44-49. [CrossRef] [PubMed]

38. Zhang, Y.-J.; Zhang, L.; Huang, X.-L.; Duan, Y.; Yang, L.-J.; Wang, J. Association between cigarette smoking and impaired clinical symptoms in systemic sclerosis: A review. Cell. Immunol. 2017, 318, 1-7. [CrossRef] [PubMed] 